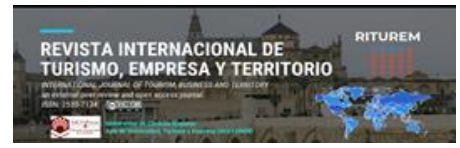

Cita bibliográfica: Serrano García, $\mathrm{M}^{\mathrm{a}}$ (2020). La ordenación legal de los establecimientos de apartamentos turísticos en Andalucía. Revista Internacional de Turismo, Empresa y Territorio, $4 \quad$ (2), 212-220 https://doi.org/10.21071/riturem.v4i1.13118

\title{
La ordenación legal de los establecimientos de apartamentos turísticos en Andalucía (España)
}

\section{The legal regulation of tourist apartment establishments in Andalusia (Spain)}

\author{
María Serrano García ${ }^{1 *}$
}

\section{Resumen}

En este trabajo se intentan identificar y aclarar los contenidos en materia de ordenación turística del actual Decreto 194/2010 de 20 de abril, que regula este tipo de establecimientos de apartamentos turísticos en Andalucía, así como las modificaciones posteriores realizadas por la Administración Turística andaluza hasta la actualidad. Para delimitar el concepto de "apartamentos turísticos" y su diferenciación de la tipología de "viviendas vacacionales" o "viviendas de fines turísticos", este trabajo aborda la conceptualización de este término, sus implicaciones prácticas en la explotación como negocio turístico de estos establecimientos, sus clasificaciones administrativas y el régimen del servicio de alojamiento resultante, de acuerdo con la normativa de ordenación turística de Andalucía.

Palabras clave: apartamento turístico, ordenación turística, servicio de alojamiento, Andalucía, España

\begin{abstract}
:
This paper attempts to identify and clarify the contents regarding tourism management of the current Decree 194/2010 of April 20, which regulates this type of tourist apartment establishments in Andalusia, as well as the subsequent modifications made by the Andalusian Tourist Administration until the actuality. To delimit the concept of "tourist apartments" and its differentiation from the typology of "holiday homes" or "homes for tourist purposes", this work addresses the conceptualization of this term, its practical implications in the operation as a tourist business of these establishments, its administrative classifications and the resulting accommodation service regime, in accordance with the Andalusian tourism regulations.
\end{abstract}

Keywords: tourist apartment, tourist planning, accommodation service, Andalusia, Spain

\section{Introducción}

En este artículo trataré de analizar la figura de los establecimientos de apartamentos turísticos en Andalucía, haciendo un recorrido cronológico a través de la normativa sectorial que los regulan. Aunque los establecimientos de apartamentos turísticos están regulados específicamente en el Decreto 194/2010, de 20 de abril, esta figura ya aparecía recogida en la Ley de 12/1999 de 15 de diciembre del Turismo y, posteriormente, en la Ley 13/2011, de 23 de

\footnotetext{
${ }^{1}$ Licenciada en Derecho y Master en Políticas Territoriales de Empleo. Socia consultora de la empresa de consultoría turística ADEITUR. E-mail de contacto: maría.adeitur@gmail.com * Autora para la correspondencia 
diciembre, del Turismo de Andalucía. Esta última supuso una adaptación a las nuevas circunstancias del sector y al marco normativo vigente en ese momento. Con esta ley se perseguía, entre otros objetivos, que la normativa aplicable respondiera a lo establecido en el Estatuto de Autonomía para Andalucía y a la regulación de las competencias de las Administraciones Locales establecida por la Ley 5/2010, de 11 de junio, de Autonomía Local de Andalucía, que exigía una revisión de la normativa turística. Por último, la ley 13/2011 deroga la Ley 12/199, de 15 de diciembre, en lo que la contradiga o se oponga a lo establecido en ella.

Entre la publicación de ambas leyes, entró en vigor el Decreto 194/2010 de 20 de abril, que regula este tipo de establecimientos de apartamentos turísticos de forma exhaustiva y precisa. Por tanto, en el año 2011, estas eran las dos normas que regulaban la figura alojativa de los apartamentos turísticos. No obstante, posteriormente ha habido importantes modificaciones legales que afectan al Decreto 194/2010, recogidas en la Orden de 16 diciembre del 2013, en el Decreto 28/2016 de 2 de febrero y en la Orden de 11 noviembre del 2016, principalmente. Por último, la reforma más reciente, aplicable a este tipo de establecimientos de alojamiento turístico, se recoge en el Decreto-Ley 2/2020, de 9 de marzo, de mejora y simplificación de la regulación para el fomento de la actividad productiva de Andalucía.

Comenzaré a analizar esta figura de alojamiento turístico con su definición, recogiendo lo establecido en el artículo 38 de la Ley 12/1999, dónde los contempla como: "un tipo de establecimiento de alojamiento turístico y son aquellos destinados a prestar el servicio de alojamiento turístico que estén compuestos por un conjunto de unidades de alojamiento y que sean objeto de comercialización en común por un mismo titular". Dichas unidades podrán ser apartamentos propiamente dichos, villas, chalés, bungalows o inmuebles análogos, "debiendo disponer del mobiliario y de las instalaciones adecuadas para la conservación, elaboración y consumo de alimentos y bebidas dentro de cada unidad de alojamiento".

Ya en esta norma se establecen los parámetros básicos definitorios de este establecimiento de alojamiento turístico, aludiendo, entre otros requisitos, al hecho de que deben estar compuestos por un conjunto de unidades de alojamiento, excluyendo de esta categoría el supuesto de una unidad alojamiento.

Por su parte, en el artículo 44 de la Ley 13/2011, al definir qué es el establecimiento de apartamento turístico, se pronuncia en el mismo sentido que el anterior, recogiendo los requisitos siguientes:

1. Son apartamentos turísticos los establecimientos destinados a prestar el servicio de alojamiento turístico, compuestos por un conjunto de unidades de alojamiento que cuentan con mobiliario e instalaciones adecuadas para la conservación, elaboración y consumo de alimentos y bebidas, y que cumplen los restantes requisitos establecidos reglamentariamente.

2. Las unidades de alojamiento que integran estos establecimientos podrán ser, según su tipología constructiva y configuración, apartamentos, villas, chalés, bungalós o inmuebles análogos.

3. Los establecimientos de apartamentos turísticos se clasifican en dos grupos:

a) Edificios/complejos: son aquellos establecimientos integrados por tres o más unidades de alojamiento que ocupan la totalidad o parte independiente de un edificio o de varios, disponiendo de entrada propia y, en su caso, ascensores y escaleras de uso exclusivo. 
b) Conjuntos: son aquellos establecimientos integrados por tres o más unidades de alojamiento ubicadas en un mismo inmueble o grupo de inmuebles, contiguos o no, ocupando sólo una parte de los mismos.

4. Los apartamentos turísticos se someterán, en todo caso, al principio de unidad de explotación, debiendo cumplir, además, los restantes requisitos establecidos reglamentariamente.

Esta definición profundiza en las características, incluyendo que se clasifican en dos grupos y que el conjunto de unidades de alojamiento necesarias se concreta en 3 o más unidades. Más adelante definiremos qué es una unidad de alojamiento.

¿Qué ocurre cuando se trata de 1 o 2 unidades de alojamiento? ¿Qué normativa se le aplica?. Pues, en este caso, se aplica el Decreto 28/2016, de 2 de febrero, para Viviendas con Fines Turísticos, teniendo la misma consideración y consecuencias fiscales que éstas.

\section{EI Decreto 194/2010, de 20 de abril de establecimientos de apartamentos turísticos de Andalucía}

Debemos de tener en cuenta que este Decreto entró en vigor cuando aún no se había publicado la Ley 13/2011 de Turismo de Andalucía. No obstante, analizaremos a continuación, el contenido del Texto Consolidado del Decreto 194/2010 elaborado por la Consejería de Turismo, que ya tiene en cuenta lo preceptuado en la Ley 13/2011 y otras modificaciones posteriores como las contenidas en la Orden de 16 diciembre del 2013, las del_Decreto 28/2016, de 2 de febrero, de las viviendas con fines turísticos y la Orden de 11 de noviembre de 2016 por la que se modifican anexos de diferente normativa turística, incluido el Decreto 194/2010, de 20 de abril, que nos ocupa.

Terminaremos este artículo con la última modificación introducida en estos establecimientos de alojamiento turístico a través del R.D. 2/2002 de 9 de marzo de mejora y simplificación de la regulación para el fomento de la actividad productiva de Andalucía.

Hasta la publicación de este Decreto, Andalucía carecía de una regulación específica y exclusiva para los apartamentos turísticos. Este Decreto 194/2010 viene a dar cumplimiento al mandato de desarrollo reglamentario dispuesto en el artículo 38.3 de la Ley 12/1999, de regular los términos concretos en los que los apartamentos deben ponerse a disposición del cliente.

El artículo 1.2 b) del Decreto 194/2010 los define de la siguiente manera: "el que esté compuesto por un conjunto de unidades de alojamiento, en las condiciones previstas en el artículo 9, destinado a prestar el servicio de alojamiento turístico, que cuenten con mobiliario e instalaciones adecuadas para la conservación, elaboración y consumo de alimentos y bebidas dentro de cada unidad de alojamiento, y que sean objeto de explotación en común por una misma persona titular.

Por tanto, las características o requisitos de este tipo de establecimiento de alojamiento turístico son:

- Destinados a prestar servicio de alojamiento.

- Compuesto por un conjunto de unidades de alojamiento.

- Que cuentan con mobiliario e instalaciones adecuadas para la conservación, elaboración y consumo de alimentos y bebidas.

- Explotados en común por una misma persona titular (o empresa). La titularidad para la explotación no tiene por qué ser la propiedad del mismo sino cualquier otro título 
suficiente en derecho para gestionar con fines turísticos el conjunto de unidades de alojamiento que conforman establecimiento.

Vamos a desglosar cada uno de los requisitos o características de este tipo de establecimientos de alojamiento turístico.

\subsection{Requisitos del servicio de Alojamiento}

Como hemos visto una de las características definitorias de los establecimientos de apartamentos es que presten servicio de alojamiento, pero ¿pueden prestar servicios complementarios propios de la industria hotelera?.

Atendiendo a lo recogido e artículo 5.5 entendemos que sí pueden prestarse otros servicios complementarios al del alojamiento en los establecimientos de apartamentos, ya que recoge expresamente que: "Cuando en el establecimiento de apartamentos turísticos se oferten servicios complementarios cuya prestación se lleve a cabo por empresas distintas a la entidad explotadora de aquél, se deberá informar a la persona usuaria de dicha circunstancia. A tal efecto, en cada unidad de alojamiento se pondrá a disposición de las personas usuarias material impreso con la relación de estos servicios y la identificación de las empresas responsables de su prestación”.

No obstante, cuando un titular tenga 1 o 2 apartamentos solamente, se regulará por la normativa aplicable a las Viviendas con Fines Turísticos y, en este caso, sólo se podrá prestar el servicio de alojamiento.

El artículo 9 de este Decreto recoge que deben componerse de 3 o más unidades de alojamiento cuando define estos establecimientos, atendiendo a su clasificación. No obstante, hay que tener en cuenta dónde se ubican. Si se encuentran en edificios no contiguos deben estar a $1 \mathrm{~km}$ o menos de la conserjería (si esta es requerida según las llaves) o de la oficina de la empresa explotadora. En el supuesto de que no sea requerida conserjería, deberán estar a $1 \mathrm{~km}$ o menos unos de otros. En todo caso deben ser 3 o más.

Se define la "unidad de alojamiento" en el artículo 1.2 a) como la pieza independiente de un establecimiento de apartamentos turísticos para uso exclusivo y privativo del usuario, compuesta como mínimo por salón-comedor, cocina, dormitorio y baño o aseo.

Por tanto, estas son las exigencias o características generales de infraestructura que deben cumplir cada unidad de alojamiento que componga un establecimiento de apartamentos turísticos. Se exige que cuente con cocina propia cada una, pudiendo, o no, estar integrada la misma en el salón-comedor. Como vemos, la misma debe estar equipada con lo electrodomésticos que permitan al alojado elaborar y conservar sus alimentos y bebidas.

Como hemos señalado anteriormente, se exigen tres o más unidades de alojamiento para conformar un establecimiento de apartamentos turísticos. Así cuando define estos establecimientos en el artículo 9, atendiendo a su clasificación, tanto para el grupo Edificios/Complejos, como para el Grupo Conjuntos, recoge lo siguiente:

- "Pertenecen al grupo edificios/ complejos aquellos establecimientos integrados por tres o más unidades de alojamiento que ...”.

- "Pertenecen al grupo conjuntos aquellos establecimientos integrados por tres o más unidades de alojamiento ubicadas...”. 
Como hemos señalado anteriormente, no se aplica este Decreto ni, por tanto, constituye establecimiento de alojamiento turístico la explotación de 1 o 2 unidades de alojamiento, entendiéndose en este caso que se regulan como Viviendas con Fines Turísticos.

Uno de los requisitos de infraestructura que se requiere para estos establecimientos de alojamiento es que cada unidad de alojamiento (apartamento) cuente en su interior con el espacio y equipamiento necesario que permita al cliente consumir y elaborar alimentos. En concreto, cada apartamento debe tener al menos: salón-comedor, dormitorio, cocina y baño (o aseo). En todo caso, no puede tratarse de cocina compartida entre varios apartamentos (unidades de alojamiento). Respecto a si la cocina puede estar integrada en el salón o no, depende de la categoría (llaves) del establecimiento). De esta forma cuando se trata de apartamentos de 3 llaves, esta pieza (cocina), debe estar independiente, siempre que las unidades de alojamiento que integren el establecimiento sean de dos dormitorios o más. En aquellos de 1 o 2 llaves no es una exigencia.

Esta principio de unidad de explotación para los establecimientos de apartamentos turísticos ya aparecía recogido en el art. 38 de la Ley 12/199, así como en el artículo 44.4 de la Ley 13/2011.

Esta exigencia se detalla en el artículo 5 de este Decreto: Cada establecimiento de apartamentos turísticos se someterá, en todo caso, al principio de unidad de explotación, correspondiéndole su administración a un único titular. Añadiendo en su punto 4 que éste habrá de asumir continuadamente la explotación de la totalidad de las unidades de alojamiento del establecimiento.

El titular de la explotación no tiene por qué coincidir con la propiedad de los apartamentos, sino que puede ser un tercero, una empresa especializada en la actividad de gestión y comercialización de alojamientos turísticos, que suscriba el correspondiente contrato con la propiedad para estos fines. Esta empresa titular de la explotación de los apartamentos será la responsable de cualquier incidente derivado del alquiler de los mismos y la que debe instar la inscripción en el Registro de Turismo de Andalucía.

Respecto a lo que se entiende como "empresa explotadora" este tema se aborda en el artículo 4, recogiendo que tendrán la consideración de empresas explotadoras de establecimientos de apartamentos turísticos las personas físicas o jurídicas, propietarias o no de los apartamentos, que presten de forma habitual y profesional servicios de alojamiento en los mismos facilitando, mediante precio, uso o disfrute ocasional de los mismos a las personas usuarias y que consten como tales en la inscripción de los correspondientes establecimientos de apartamentos turísticos en el Registro de Turismo de Andalucía.

Se presumirá la habitualidad cuando se ofrezca la prestación del servicio de alojamiento a través de cualquier medio de difusión o publicitario o cuando se facilite alojamiento en una o más ocasiones dentro del mismo año por tiempo que, en conjunto, exceda de un mes. En este caso difiere de las VFT para las que se presume habitualidad y finalidad turística cuando la vivienda sea comercializada o promocionada en canales de oferta turística, entendiendo como tales las agencias de viaje, las empresas que medien u organicen servicios turísticos y los canales en los que se incluya la posibilidad de reserva del alojamiento.

No tendrán la consideración de empresas explotadoras los titulares de uno o dos apartamentos, entendiéndose en este caso, que se destinan a viviendas con fines turísticos, como hemos recogido anteriormente. 


\subsection{La clasificación de los establecimientos de apartamentos turísticos.}

Los establecimientos de apartamentos turísticos se clasifican obligatoriamente en grupos, categorías, modalidades y, opcionalmente, en especialidades (artículo 8).

Existen dos Grupos, que son los dos siguientes (artículo 9):

- Edificios/complejos

- Conjuntos

Pertenecen al grupo edificios/ complejos aquellos establecimientos integrados por tres o más unidades de alojamiento que ocupan la totalidad o parte independiente de un edificio o de varios, disponiendo de entrada propia y, en su caso, ascensores y escaleras de uso exclusivo, pudiendo adoptar la denominación de "edificio de apartamentos turísticos" o "complejo de apartamentos turísticos" en el caso de varios edificios.

Pertenecen al grupo conjuntos aquellos establecimientos integrados por tres o más unidades de alojamiento ubicadas en un mismo inmueble o grupo de inmuebles, contiguos o no, ocupando sólo una parte de los mismos, en los que se presta el servicio de alojamiento turístico bajo unidad de explotación.

Esta clasificación en estos dos grupos también se recoge en el artículo 44.3 de la Ley 13/2011, como vimos en inicio.

Respecto a las categorías, los apartamentos se clasifican por "llaves", desde una llave hasta cuatro llaves (Artículo 11).

1. Los establecimientos de apartamentos turísticos del grupo edificios/ complejos se clasifican en las categorías de cuatro, tres, dos y una llave.

2. Los establecimientos de apartamentos turísticos del grupo conjuntos se clasifican en las categorías de dos y una llave.

Las Modalidades, que dependen del lugar en el que se ubiquen, son las siguientes (art. 12):

a) Playa.

b) Ciudad.

c) Rural.

d) Carretera.

Las especialidades, por su parte, son de carácter voluntario y encontramos las siguientes:

- Atendiendo a las características arquitectónicas: Monumentos e inmuebles protegidos.

- Atendiendo a los servicios prestados y a la tipología de la demanda a la que se dirija: de naturaleza, deportivos, familiares,

Es importante resaltar que los establecimientos de apartamentos turísticos están afectas a la prestación del servicio de alojamiento turístico desde el momento que se inscriben en el Registro de Turismo de Andalucía, quedando prohibido durante su vigencia destinar aquéllas a un uso distinto, como el residencial, bajo cualquier título y, expresamente, a la actividad de alquiler de vivienda.

\subsection{La normativa posterior de modificación.}

A continuación, recogemos, escuetamente, otra normativa posterior que ha venido a modificar diferentes aspectos de los establecimientos de apartamentos turísticos en Andalucía, 
por lo que habrá que tener siempre en cuenta estos cambios para iniciar o transformar un proyecto de apartamentos:

1.) La Orden de 16 diciembre del 2013, por la que se modifican varios anexos del Decreto 194/2010. Esta Orden introduce algunas modificaciones respecto a requisitos y especialidades de los apartamentos turísticos, en los siguientes Anexos del Decreto 194/2010: Anexo I, título del Anexo III, y Anexo IV.

2.) Decreto 28/2016, de 2 de febrero, de las viviendas con fines turísticos y de modificación del Decreto 194/2010. En este Decreto se introducen modificaciones para adecuarse a la Ley 13/2011, respecto a la definición de los establecimientos de apartamentos turísticos del grupo Conjuntos.

- Se flexibilizan distintos requisitos relativos a la acreditación de la unidad de explotación y a la exhibición de las placas identificativas.

- Se incorpora la especialidad casas-cueva vinculada a la modalidad ciudad.

- Recoge los requisitos relativos a la clasificación cuyo cumplimiento puede ser objeto de exención para los establecimientos del grupo conjuntos, compensándolos mediante la oferta de determinados servicios complementarios o condiciones adicionales, según lo contenido en el Anexo VI del Decreto 194/2010. De esta manera, se da un trato similar a los establecimientos de apartamentos turísticos del grupo conjunto respecto a los del grupo edificios/complejos, para los que ya se preveía este régimen de exención.

3.) Posteriormente, la Orden de 11 noviembre del 2016, modifica determinados Anexos del Decreto 194/2010, de 20 de abril, en concreto el:

- Anexo I: Requisitos mínimos para el grupo de edificios/complejos de apartamentos turísticos

- Anexo V: Requisitos relativos a la clasificación cuyo cumplimiento puede ser objeto de exención

- Anexo VI: Compensaciones necesarias para la exención de requisitos relativos a la clasificación

Por último, con la entrada en vigor del Decreto-Ley 2/2020 de 9 de marzo se reforma la Ley 13/2011 en múltiples artículos, afectando a la figura de los establecimientos de apartamentos turísticos. En este sentido se produce una importante novedad y es que todos los establecimientos de apartamentos turísticos podrán constituirse como propiedad horizontal. De esta manera, la nueva redacción dada al artículo 42 de la Ley 13/2011 queda con el siguiente texto: "en los supuestos en los que se permita por el planeamiento urbanístico, los establecimientos de alojamiento turístico podrán constituirse en régimen de propiedad horizontal o figuras afines, estando sometidos en todo caso al cumplimiento del principio de unidad de explotación".

Al referirse en general, sin distinguir, a "los establecimientos de alojamiento turístico", incluye a los establecimientos de apartamentos turísticos, independientemente de su grupo y categoría, superando limitaciones anteriores incluidas en la normativa.

Llegados a este punto, considero importante resaltar la discrepancia de intereses que puede tener lugar entre los propietarios de apartamentos para uso residencial y la explotación de otros para uso turístico, cuando ambos se ubiquen en el mismo inmueble 
Esta contraposición de intereses entre la comunidad local y la comunidad turística, ya se ha puesto de manifiesto determinadas zonas turísticas y destinos, provocando reacciones en contra por parte de los residentes que ven alterada su estancia vacacional o sus hábitos en su vida normal. Esta reacción guarda relación con otro concepto que ha aflorado en el ámbito de la gestión turística y es el de "turismofobia".

Por último, hay que destacar que se ha producido una modificación a la Ley de Propiedad Horizontal en el Real Decreto-Ley 21/2018, de 14 de diciembre, añadiendo un párrafo 12 al artículo 17, que recoge las facultades que tiene la Junta de Propietarios con respecto a la explotación de apartamentos turísticos en su inmueble.

"párrafo 12. El acuerdo por el que se limite o condicione el ejercicio de la actividad a que se refiere la letra e) del artículo 5 de la Ley 29/1994, de 24 de noviembre, de Arrendamientos Urbanos, en los términos establecidos en la normativa sectorial turística, suponga o no modificación del título constitutivo o de los estatutos, requerirá el voto favorable de las tres quintas partes del total de los propietarios que, a su vez, representen las tres quintas partes de las cuotas de participación. Así mismo, esta misma mayoría se requerirá para el acuerdo por el que se establezcan cuotas especiales de gastos o un incremento en la participación de los gastos comunes de la vivienda donde se realice dicha actividad, siempre que estas modificaciones no supongan un incremento superior al 20\%. Estos acuerdos no tendrán efectos retroactivos.»

Pero ¿Podrá la Junta de Propietarios prohibir la explotación para el turismo de determinados pisos en su inmueble?

Lo que la norma recoge es que las comunidades de propietarios podrán adoptar medidas restrictivas o de cierto control respecto de la explotación turística de determinados pisos/apartamentos de su inmueble: "podrán acordar limitaciones o condiciones" para el ejercicio de la actividad turística en su inmueble. Como vemos no recoge expresamente que puedan prohibir dicha actividad por un acuerdo. Habrá que estar a la jurisprudencia para determinar la capacidad y alcance de estas limitaciones al ejercicio de la actividad turística en el inmueble. En todo caso la adopción de estos acuerdos restrictivos o condicionantes deben tener su fundamento en la preservación del interés general y demostrar que la explotación turística daña este interés general.

\section{Una reflexión final.}

Quiero concluir con una llamada de atención sobre la importancia de arbitrar mecanismos e instrumentos que permitan esa convivencia de la que hablábamos en principio, para que la comunidad local no se posicione en un rechazo a la actividad turística, sino que la perciba como una vía hacia un modelo de desarrollo turístico sostenible, que propicie un reparto equitativo de la riqueza. 